\title{
O TRIbUNAL DO JÚRI EM PôRTo ALEGRE
}

\section{PEDRO VERGARA}

Agradecendo $o$ banquete que lhe ofereceram, a 15 de março de 1952, os meios jurídicos de Pôrto Alegre, o dr. PEDRO VERGARA proferiu o seguinte discurso:

"Meus caros amigos.

Não poderia eu aspirar a distincão maior do que esta.

Quisestes, todavia, requintá-la, quando escolhestes para vosso intérprete, nesta hora, a personalidade ilustre de Glicério Alves, a quem me ligam os laços da estima fraternal - meu condiscípulo do ginásio, meu companheiro de lutas e porfias na vida pública, meu colega de bancada, quando eu e êle tínhamos a honra de representar o Rio Grande na Câmara Federal.

Homem de excepcional energia de caráter, cidadão na mais alta e na mais límpida acepcão do vocábulo - riograndense que esteriotipa, na sua vida e na sua individualidade, as mais belas tradições morais do nosso povo - jurista e advogado que ama engrandece a sua profissão, com a nobre consciência dos seus direitos e dos seus deveres - êle é bem o vosso portavoz, e ninguém mais do que êle - vosso amigo e meu amigo - saberia exprimir, com maior afeto e maior compreensão, a vossa generosidade, neste gesto.

Agradeço-vos, pois, do fundo do coração - primeiro, a festr que me ofertais - e, em seguida, o arauto que escolhestes para ofertá-la.

Glicério Alves fez referência a cada um dos meus estudos melhor direi - de minhas audácias e de minhas intromissões no campo do direito penal - tão atravancado de problemas velhos e novos.

Sem dúvida alguma, certo número dessas questões já foram resolvidas, de modo positivo ou negativo, na legislação dos povos cultos. Esse novo direito se inicia em 1921, se estadeia, visando a rumos definitivos, em 1930, assume o seu apogeu em 1937, se decanta, se corrige e se retifica, em 1940. 
O Código Argentino, o Código Italiano, o Código Suíço, o Código Brasileiro - eis os planos superpostos dêsse caminho ascencional. E' essa, por assim dizer, uma codificação pacificadora. Poderia parecer, até, uma transação e um compromisso.

Durante mais de meio século, em verdade, as doutrinas penais se defrontam, se desafiam, se chocam.

Mas, não tardou que ao classicismo puro de Romagnosi sobretudo de Carmignani e de Carrara, se seguissem os cismas protestantes dos novi-clássicos; e então se começaram a ouvir as grandes vozes de Ortolan, de Impallomeni, de Lucchini, de Crivellari, de Chauveau Helie, de Haus; e a imensa autoridade de Saleilles, formada nesse ambiente de renovação e reforçada, cada dia, pela comprovação dos seus conhecimentos de todo o direito, pôde atuar e pesar sôbre o magistério, sôbre a magistratura e sôbre as leis.

Mais depressa que o classicismo, à sua vez, e quando ainda mal seguro de seus princípios, se cindiu e entrou em crise a escola positiva. Ferri, com a sua sociologia penal, não podia sonegar os exageros antropológicos de Lombroso; e Garofalo - ainda dentro do positivismo - fazia reverter o direito de punir a critérios de pura moralidade.

Essa luta dos positivistas italianos, apenas disfarçada pela idéia de que todos estavam construindo a sua ciência, cada qual com o seu esfôrço distinto e sem conflito ou negação, iria repercutir nos diversos países do Velho Mundo, para fazer nascer a escola francesa e prosperar a escola alemã, baseadas, uma e outra, nos postulados da higidez e da normalidade.

No meio dêsse tumulto, em que o positivismo se desarticulava, afanado por encontrar a sua própria razão de ser, na vã e fugitiva unidade do seu pensamento - se levanta e se alteia, como o farol que tenta iluminar o oceano, o gênio, a uma só vez fecundo e profundo de Gabriel Tarde.

E' quando as leis da imitação e identidade, expostas na majestade de um estilo a Fustel de Coulanges, se assenhoreiam das pesquisas, para fazer de novo que a intuição sociológica sobrelevasse os dados da Antropologia, da Psiquiatria e da Medicina.

Êsses conflitos não podiam levar a qualquer espécie de acôrdo, no interior das escolas, onde as personalidades consulares, os valores mais altos, se digladiavam e, até, de certo modo, se destruiam, entre si.

E o que mais feria a sensibilidade e o bom-senso de quem permanecia como espectador, sereno e distante, em face dos clássicos que brigavam com os clássicos, dos positivistas que brigavam com os positivistas - e de positivistas e de clássicos, que se agrediam, assim mesmo, uns aos outros, na certeza de que detinham tôda a verdade, mesmo em pedacos - era o julgamento dos criminosos ou dos não criminosos, à luz de doutrinas tão contradi- tórias, e sob a inspiração de sábios tão desautorizados, dentro de seus próprios agregados culturais.

E' essa, aliás, a contingência do direito em geral: não sendo ciência exata, mas ciência social, sujeita a retificações muito mais rápidas - o que hoje tem por certo, já pode estar errado amanhã; e quem tem o direito e a lei a seu favor, num dia, pode já não tê-los, no dia seguinte.

Mas, se isso é prejudicial no direito privado, muito mais o será no direito de punir, onde estão em jôgo a vida, a liberdade e a honra dos cidadãos.

Eis por que o legislador moderno - prescrutando, imparcialmente, as doutrinas - não se deteve nas suas abstrações, não se deixou levar pelos seus excessos de generalização, não quis ser, êle também, doutrinador, e muito menos criador de dogmas e mitos.

Não encontrando nas teorias tôda a verdade, mas apenas uma parte da verdade - e essa mesma correspondente ao seu conteúdo de observacão e de pragmatismo - só podia seguir e só seguiu, de fato, o único caminho que lhe aconselhava a utilidade e a exeqüibilidade das leis: tirou de cada escola e de cada concepção penal, a sua quantidade ponderável de experiência.

Assumindo, pois, a posição de verdadeiro juíz, diante das controvérsias - e tendo em mente, apenas, a preocupação estatal de manter a segurança e a prosperidade, defendendo os cidadãos contra a ilicitude e a violência - o legislador dos nossos dias só se deteve nas doutrinas, em razão e por fôrça da sua objetividade, e esta se conceituou no seu espírito e na sua clarividência, como psicologia humana e como fato social.

Fora daí, para a sua capacidade de reconstruir e de reformar, estava o devaneio, ou, se quiserem, a metafísica, alimentada de conjecturas ou de hipóteses mais ou menos ilegítimas.

Vemos, então, ao cabo dêsse penoso trabalho seletivo, que o direito penal positivo, contemporâneo - eqüidistante e neutro - fugiu, de um lado, àquilo que se poderia chamar a geometria jurídica da escola clássica, e, de outro lado, ao impreciso determinismo psíquico-orgânico e social da escola positiva.

Mas, exatamente, sob o império de uma evidência, comprovada pela consciência popular e pela psicologia aplicada, na prática dos julgamentos e na execução e cumprimento das penas - o novo direito adotou, como postulados e diretivas, definidoras de suas pretensões, nada mais nada menos que os fundamentos de que partiam, para as suas insolúveis contendas, as duas grandes escolas que disputavam, irredutíveis, a verdade, no campo penal.

Assim, os Códigos do Brasil, da Itália, da Suíça - para falar, apenas, nos principais, e que podem servir de padrão e roteiro, ao direito penal do futuro, por sua técnica magistral $\epsilon$ seu conteúdo de experiência - se esteiam nestes princípios, que, 
há vinte ou trinta anos, representavam os dois polos do pensamento, sôbre essa matéria: a responsabilidade moral e a personalidade do delinqüente.

Hoje, conseqüentemente, para o legislador, não há mais escola clássica, nem positiva; há o crime e o delinqüente; e as tímidas, inadequadas ou vacilantes concessões que os códigos, saídos do direito natural ou do contrato social, faziam, no século passado, depois do grande cisma positivista, à psicologia do delinqüente à idéia de recuperação social do homem que se degrada no delito, adquiriram a sobrevalência e já dominam por completo o conceito da pena.

Em verdade, já se converteram elas hoje no vigoroso pensamento de que o direito penal só vale e só importa, pelos seus resultados, quando combate a criminalidade, sob o duplo aspecto da sua eclosão e da sua reincidência.

Salvaguarda, pois, da personalidade humana - pela afirmação e reintegração dos poderes volitivos, dissociados no delito, e individualização da pena, para que essa mesma personalidade seja fixada e restaurada - eis o direito penal positivo, em tôda a sua profundidade e em tôda a sua compreensão.

Mas, se a questão penal está, assim, resolvida, nesse esquema, - é, de outro lado, aí, que reside e daí é que brota a gama tôda de problemas secundários e correlatos que torturam os criminalistas e que provocam a enorme floração de monografias e de ensaios, de que se enriquece, no presente, a literatura penal da Itália e da Alemanha, tanto quanto de nossa América Latina.

Se a base, realmente, dos códigos, é a personalidade do delinqüente, mesmo quando se o encara como sêr moral, dotado de livre arbítrio - e se o mais intricado de todos os problemas que debate o homem, é o próprio homem - bem se pode perceber que o direito penal encontrou o seu caminho certo, mas que êsse caminho está cheio de curvas, de ascenções e de pendentes; que é um caminho longo e penoso; que está por vêzes encoberto de sombras e de noites indevassáveis, e que, não raro, os abismos do êrro e da injustiça se despencam nas suas margens.

Basta considerar que o estudo da personalidade delinqüente se apoia na Medicina, na Psiquiatria, na Psicologia e na Sociologia, sem falar na contribuição de outros conhecimentos e outras ciêr:cias, em que se difunde e em que se especializa a curiosidade humana, sob o tropismo da verdade, o centro planetário do pensamento.

Mas, os médicos se perturbam diante dos casos clínicos e se desafiam nos diagnósticos e prognósticos; os psiquiatras, quando não podem, desde logo, surpreender a loucura maníaco-depressiva ou a demência precoce, ou quando não descobrem, como qualquer mortal, uma oligofrenia ou certas formas bem conhecidas de delírio, de epilepsia ou de histeria, ficam perplexos, indecisos, inseguros, e por isso mesmo se contradizem uns aos outros, quando penetram naquela zona "mitoyenne", em que a doença mental e o simples desequilíbrio das faculdades se interpenetram, num sistema de fronteiras móveis ou de terras de ninguém; os psicólogos - êsses, com a sua infinidade de teorias e de interpretações sôbre a inteligência, sôbre a vontade, sôbre os afetos, sôbre os impulsos, sôbre a memória, sôbre o raciocínio, sôbre cada um dos sentimentos humanos - com a sua psicologia clássica, dissociativa dos fatores psíquicos, a sua psicologia da forma, a sua psicologia do comportamento, a sua psicologia individual, a sua psicanálise - êsses, permanecem diante do homem normal ou anormal, como diante de um caleidoscópio de funções, e, às mais das vêzes, como na Psiquiatria, as suas conclusões não passam de hipóteses, de doutrinas, de teses, que outros psicólogos vêm e contestam, com igual desembaraço, com observações próprias e com o mesmo poder de convicção; e o mistério do homem, êsse desconhecido, permanece e continua; e os sociólogos, diante da imensidade do conhecimento humano, que a sua ciência exige - em razão, precisamente, do seu dever de achar as causas dos fenômenos sociais e formular as suas leis - êsses são, de todos, os menos seguros e os menos autorizados, a não ser quando aceitamos como dogmas, e não discutimos, os seus sistemas, que correspondem às nossas tendências ou às nossas aspirações.

E é, não obstante, com essa colaboração das ciências e dos cientistas, em perene mudança, e que revisam, todos os dias, as suas descobertas e os seus conhecimentos, que tem de ver-se o juíz, quando a personalidade do delinqüente e com ela a sua responsabilidade moral, são submetidas ao seu exame e, mais do que isso, ao seu julgamento.

Eis por que sustento, que o direito penal contemporâneo, plasmado, já, em normas e preceitos, está prenhe de novos e difíceis problemas.

Também ao criminalista incumbe, nesse particular, tarefa árdua - muito mais rude, ainda, por certo, que as distribuídas aos psiquiatras, aos psicólogos, aos sociólogos - porque a êle se impõe o dever, sôbre todos austero, de captar os ensinamentos mais adequados e mais seguros, daquelas disciplinas, e ajustá-los à consciência jurídica, no seu trabalho de provar e persuadir.

A êsses dados, pois, que as ciências correlatas oferecem, deve o criminalista aduzir o problema do direito; mas êste não se compõe, apenas, da dogmática, ou seja, do pensamento expresso ou oculto do legislador; envolve, também, e sobrestima a consciência popular, que repercute nos tribunais, e para onde se volta, sempre, perseguindo a realidade e a verdade, o homem de Estado, quando legisla. 
Meus caros amigos, ao dizer-vos estas cousas, tão consabidas e tão desataviadas, o que pretendo é desculpar-me de haver tentado - eu também - trazer a minha contribuição, sem dúvida inútil e inquinada de nulidades insanáveis, para o exame e a aplicação do direito penal.

Tenho a plena consciência das minhas fraquezas e das minhas deficiências, e posso confessar-vos, serenamente, que o número de páginas que rasguei, sem publicar, é possìvelmente igual ao das outras que correm mundo, publicadas.

Diante de mim, posso dizer-vos, do mesmo modo e com a mesma lealdade, que só tenho encontrado dificuldades e dúvidas, e que tudo quanto escrevi e difundi, sôbre o crime e sôbre a pena, sôbre o delinqüente e sôbre a sua recuperação, não passa de tentames, de hipóteses, de aproximações, e muitas vêzes, dè anelos ou de simples adesão ou conformidade.

Pode ser que nesse interêsse e nesse amor pela ciência penal, tenha atingido, certo e direto, a verdade; mas, não o sei, salvo a própria convicção, que é, na generalidade dos casos, uma verdade para uso interno ou doméstico. .

Quero, não obstante, responsabilizar-vos por essas investidas e essas incursões, através de uma ciência tão bela e tão árida, ao mesmo tempo.

Se sou criminalista, sou muito menos criminalista brasileiro que riograndense.

Os livros que produzi e que tiveram maior repercussão, e pelos quais estou, sem dúvida, recebendo, neste momento, esta prova desvanecedora de estima e de estímulo - a Legitima Defesa Subjetiva Dos Motivos Determinantes no Direito Penal e Delito de Homicidio, foram em tôda a sua matéria de fato e de pensamento, concebidos e trabalhados aqui.

O Rio de Janeiro - onde foram escritos os dois últimos só me ofereceu o tempo e a folga necessários, para a sua redação.

$\mathrm{E}^{\prime}$ por isso que nas suas páginas prevalecem, de extremo a extremo, as observações colhidas entre nós, em nossos violentos júris da capital e do interior; e os episódios e julgados mais interessantes e mais convincentes, para a demonstração dos pontos de vista sustentados, pertencem, todos, à história dos nossos pretórios e às causas célebres que agitaram o nosso fôro.

Terra de heróis e de tribunos - como se a oratória e a bravura fôssem irmãs, nas suas audácias e nos seus impulsos - o sentimento da honra ofendida criou entre nós o imperativo das reações cruentas; e a eloqüência dos oradores se abeberou da seiva e do cordial que êsses estados afetivos do pundonor destilavam.

$\mathrm{E}$, por isso, podemos dizer que o direito civil e o direito comercial, tanto quanto o processo, nos vieram do Norte, naquela contínua e duradoura e benéfica migração de juristas, partidos de
Pernambuco, de Sergipe, do Rio Grande do Norte, da Bahia, e que durante mais de meio século, fecundaram e dignificaram a justiça riograndense.

Mas, o nosso direito penal - se ressalvarmos a figura inolvi. dável de Ribeiro Dantas, quartada à magistratura e ao magistério - êsse, no seu ensino, no seu exercício, na sua doutrinação, nos seus episódios, é, precipuamente, nosso; foi e tem sido a resultante das nossas condições sociais, da nossa formação étnica, das nossas contingências históricas e especialmente dos nossos sentimentos, impregnados dessa existência bravia e romântica, livre e altaneira, que nos define e nos diferencia.

Podemos dizer, sem nenhum receio de exagêro, que tivemos, aqui, os maiores oradores da tribuna judiciária penal, e que em vão se buscará, no Brasil, para além das nossas fronteiras, alguém que houvesse manejado melhor a palavra, nos torneios do Júri, do que êsse gigante das sínteses geniais e das imagens sublimes, coloridas de filosofia e de poesia, nos improvisos fulgurantes e arrebatadores - Pereira da Cunha - vivo e imortal, ainda, em nosso culto. Ninguém superou, também - nem aqui, nem lá fora - o saber, a habilidade, o conhecimento do direito e do processo, a emoção ferreana, os arrebatamentos líricos de Plínio Casado. E quem poderá ter esquecido, na sua fluência, na sua limpidez, na sua cultura, na sua beleza literária, a palavra de João Neves, como criminalista?

E Andrade Neves Neto e Souza Lobo e Osvaldo Aranha e Flores da Cunha e Getúlio Vargas e Vieira Pires, e êsse soberbo e arrebatado Maurício Cardoso, admirável humanista, sabedor de tôda a ciência do direito e cuja voz que sobreexcedia às próprias resistências e medidas físicas, parecia tocada não sei de que estranhas e espetaculares ressonâncias cósmicas, como um responso de tormentas nas canhadas. E Alvaro Sergio Masera, que escondia, por vêzes, nas doçuras e amavios da frase e da elocução, os arremessos do leão enfurecido, mas nobre e generoso, que pulsava e rugia na sua alma? E Fausto de Freitas e Castro que levava para a tribuna os gestos, os hábitos e os recursos do professor, e que se impôs ao respeito de adversários e de juízes, pelo seu insuperável poder de argumentação e de lógica?

Mas, essas gerações que passaram ou que estão passando não edificaram glória perecível, nem plasmaram em vão, na memória do povo, a imagem do orador forense.

Os criminalistas novos do Rio Grande retomaram a tradição, como de cidade em cidade ou de píncaro em píncaro, se toma $\epsilon$ se conduz adiante a chama da pátria.

Ontem, ainda, sucumbia, num vôo aéreo, que era também um bater de asas da sua profissão, aquêle jovem de excepcionais virtudes de jurista e de tribuno, ao serviço da ciência penal e de 


$$
-146-
$$

sua prática, aquêle brilhante, aquêle perturbador, aquêle inquieto Voltaire Pires; e, ainda agora, á, está, para orgulho de todos nós, para a nossa ufania e para nossa glorificação, o primus inter pares dos nossos oradores forenses, desta hora - Itiberê de Moura.

Eis aí o Rio Grande fecundo e luminoso, onde encontrei as raízes e a fôrça da minha vocação de criminalista.

Aqui está presente um dos advogados mais eminentes e mais prestigiosos do nosso fôro.

Conheci-o na adolescência, quando ambos, estudantes, nos adestrávamos para as lides tribuníceas, em nossas caminhadas noturnas pelos subúrbios, à cata de batizados, aniversários e casamentos, onde pudéssemos ser ouvidos, no desafôgo da nossa pletora verbal, ansiosa de platéias e louvores...

Ligados desde sempre, por esta amizade que nada e ninguém destrói - é hoje com ternura fraternal que testemunho o seu triunfo e o vejo admirado e respeitado, entre os maiores e os melhores de sua classe. Estou me referindo a Valdemar do Couto e Silva.

Pois bem - naqueles tempos já distantes - havia uma escola de oratória em Pôrto Alegre, e ali se travaram os mais belos e os mais cálidos debates que o direito penal podia suscitar e desencadear, em qualquer parte.

Os mais famosos tribunos do Rio Grande se elevaram a essa cátedra e os prélios que ali dentro se acendiam parece que visavam muito mais à beleza e à majestade do verbo, e não tanto à prosaica, feia e fria verificação das provas.

Pelas horas avançadas da noite, quem passasse nas imediações daquela estranha academia, radiante de luzes, podia ouvir uma voz cavernosa e empostada que dizia: "A lua é uma vírgula de prata, engastada no infinito, para dizer que o infinito não tem ponto final". Ou então outra voz mais aberta e mais sonora, que lançava no espaço a imprecação homérica: "O homem perde com a liberdade a metade do caráter". Ou ainda nimbada de transcendência e sublimidade: "A consciência é um comprimido de Deus na alma de cada homem".

Às vezes, aquelas vozes eram truncadas, repentinamente, e o tumulto substituia o gesto harmonioso, e à música das frases perfeitas, se seguia o disparo das armas de fogo, e pelas janelas e pelas portas, irrompia, num estouro descontrolado, a multidão que há pouco enxugava, lá dentro, as lágrimas, e abafava os soluços, no encantamento dos ouvidos.

Essa escola, essa academia, êsse liceu, ficava lá encima, no píncaro da colina; à sua frente subiam as tôrres da matriz, apontando à pureza das estrelas e ao insondável mistério da divindade, de onde vêm e para onde vão os nossos destinos; e ao lado, com a sua massa enorme, e pesado como as consciências irredentas,
$-147-$

vencia o tempo o teatro, onde apenas se representam e se simulam as paixões que movem e perdem os homens.

Essa escola, essa academia, êsse liceu, onde se aprendia a eloqüência até à explosão dos entusiasmos sangrentos, quando o verbo se faz fôrça e ação - era, apenas, isto: o Tribunal do Júri de Pôrto Alegre.

Foi ali, indiscutivelmente, que se inspiraram para suas próprias palingenesias, as sucessivas gerações de criminalistas - e ali, quase todos os advogados de hoje, que foram os meus companheiros de adolescência, e sobretudo eu e Valdemar do Couto e Silva arrebatados do mesmo fervor e do mesmo culto à palavra e ao talento, conhecemos as mais radiosas e as mais fecundas vigílias da nossa vida de estudantes.

Creio, meus caros amigos, que êsse passado é ainda o meı presente, e que a minha vocação para a ciência penal nada mais é que a revivescência, a ressurreição, a frutificação daquelas emoções de outrora.

E agora que levanto a minha taca, para vos agradecer esta homenagem, levanto no mesmo gesto o coraç̃o e o espírito, para agradecer ainda mais, ao Rio Grande do Sul e a todos os seus tribunos e oradores, a todos os seus criminalistas, a todos os seus juízes, a todos os seus cidadãos, que me deram os estímulos e as oportunidades, para a realização de uma obra que é mais sua do que minha. 